\title{
Indicadores bioquímicos e hormonais de casos naturais de toxemia da prenhez em ovelhas ${ }^{1}$
}

\author{
Fábio C.O. Santos ${ }^{2}$, Carla L. Mendonça ${ }^{3}$, Alonso P. Silva Filho², Cleyton C.D. Carvalho², \\ Pierre C. Soares ${ }^{4}$ e José Augusto B. Afonso ${ }^{3^{*}}$
}

\begin{abstract}
Santos F.C.O., Mendonça C.L., Silva Filho A.P., Carvalho C.C.D., Soares P.C. \& Afonso J.A.B. 2011. [Biochemical and hormonal indicators of natural cases of pregnancy toxaemia of in sheep.] Indicadores bioquímicos e hormonais de casos naturais de toxemia da prenhez em ovelhas. Pesquisa Veterinária Brasileira 31(11):974-980. Clínica de Bovinos, Campus Garanhuns, Universidade Federal Rural de Pernambuco, Av. Bom Pastor s/n, Cx. Postal 152, Boa Vista, Garanhuns, PE 55.292-270, Brazil. E-mail: afonsojab@oi.com.br

Toxemia of pregnancy is a metabolic disorder with considerable economic impact on the production of sheep. However, the particularities of the systemic repercussion of the disorder have not yet been fully clarified. The aim of the present study was to assess the biochemical and hormonal profile of 77 ewes with a clinical diagnosis of toxemia of pregnancy and to compare the laboratory findings based on the clinical outcome: discharge (G1) or death (G2). The clinical manifestation of the disease was observed in the pre-birth period in $100 \%$ of the ewes, from which $66.2 \%(n=51)$ were discharged and $33.8 \%(n=26)$ died. A total of $55,8 \%$ of the cases were of multiple pregnancies.. Considering the parameters analyzed, cortisol, urea, AST and CK were significantly higher in G2 in comparison to $\mathrm{G} 1(\mathrm{p}<0.05)$. An increase was found in the concentration of plasma glucose, fructosamine, albumin, creatinine, $ß$-hydroxybutyrate, non-esterified fatty acids and L-lactate, with no statistically significant differences between groups $(p>0.05)$. No changes were found in cholesterol or triglycerides. A reduction in insulin levels was found, with no statistically significant difference between groups ( $p>0.05$ ). All ewes exhibited ketonuria and aciduria.
\end{abstract}

INDEX TERMS: Metabolic disease, ketoses, biochemistry clinic, cortisol, insulin.

RESUMO.- Toxemia da prenhez é considerada um transtorno metabólico de grande impacto econômico na produção de ovinos, porém as particularidades de repercussão sistêmicas deste distúrbio ainda são pouco esclarecedoras. 0 presente estudo teve por objetivo avaliar o perfil bioquímico e hormonal de 77 ovelhas com diagnóstico clínico de toxemia da penhez e comparar os achados laboratoriais de

\footnotetext{
${ }^{1}$ Recebido em 27 de junho de 2011.

Aceito para publicação em 16 de agosto de 2011.

Parte da Dissertação de Mestrado em Ciência Veterinária do primeiro autor, Universidade Federal Rural de Pernambuco (UFRPE).

${ }^{2}$ Pós-Graduando em Ciência Veterinária, Universidade Federal Rural de Pernambuco (UFRPE), Rua Dom Manoel de Medeiros s/n, Dois Irmãos, Recife, PE 52171-900, Brasil.

${ }^{3}$ Clínica de Bovinos, Campus Garanhuns, UFRPE, Av. Bom Pastor s/n, Boa Vista, Cx. Postal 152, Garanhuns, PE 55292-270. *Autor para correspondência: afonsojab@oi.com.br

${ }^{4}$ Departamento de Medicina Veterinária, UFRPE, Dois Irmãos, Recife, PE 52171-900.
}

acordo com a resolução clínica dos animais, alta hospitalar (G1) e aqueles que morreram (G2). A manifestação clinica da doença foi observada no período do pré-parto em $100 \%$ dos animais, destes $66,2 \%(n=51)$ receberam alta clínica e 33,8\% (n=26) morreram. Dos casos de toxemia da prenhez estudados havia gestação múltipla em 55,8\%. Dentre os parâmetros estudados, cortisol, uréia, AST e CK estavam mais elevados no G2 em relação ao G1 com diferenças significativas $(\mathrm{P}<0,05)$. Foi encontrado aumento nas concentrações de glicose plasmática, frutosamina, albumina, creatinina, ß-hidroxubutirato, ácido graxo não esterificado e L-lactato, porém não houve diferenças entre os grupos $(P>0,05)$. Não ocorreram alterações nas taxas de colesterol e triglicerídios. Houve redução nos índices da insulina, não havendo diferenças entre G1 e $\mathrm{G} 2(\mathrm{P}>0,05)$. Todas as ovelhas apresentaram cetonúria e acidúria.

TERMOS DE INDEXAÇÃO: Doença metabólica, cetose, bioquímica clínica, cortisol, insulina. 


\section{INTRODUÇÃO}

A toxemia da prenhez é um distúrbio metabólico e hormonal multifatorial, que acomete ovelhas no terço final da gestação, geralmente com dois ou mais fetos, acarretando elevada taxa de mortalidade dos fetos e ovelhas. Ocorre principalmente nos sistemas intensivos de produção, sendo relativamente rara em unidades de pastejo extensivo, a não ser como consequência de variações climáticas (época de seca) e falhas de manejo. (Andrews 1997, Radostits et al. 2007).

O distúrbio ocorre como consequência da maior demanda do feto por glicose que excede a energia oferecida na dieta, aumentando a lipólise e gerando elevação na síntese de corpos cetônicos, acarretando transtornos na homeostase metabólica. Clinicamente, a enfermidade caracteriza-se por sinais como apatia, amaurose, dispnéia, tremores musculares, anorexia, atonia ruminal, andar com dificuldade e prostração, que podem evoluir para a morte (Kimberling 1988, Bruére \& West 1993, Rook 2000).

As ovelhas acometidas, em geral, apresentam alterações como hipercetonemia, cetonúria, hipoglicemia, níveis elevados dos ácidos graxos não esterificados (AGNE) e cortisol, além do comprometimento da função hepática e renal (Ferris et al. 1969, Ortolani \& Benesi 1989, Bruere \& West 1993, Sargison et al. 1994, Andrews et al. 1996).

Poucos são os estudos que relatam a busca de elementos indicadores da severidade dos casos de toxemia da prenhez. Diante desta constatação, objetivou-se com este trabalho identificar os principais indicadores bioquímicos e hormonais de casos naturais da toxemia da prenhez (TP), baseado na resolução clínica desta enfermidade, ovelhas que receberam alta hospitalar ou que morreram.

\section{MATERIAL E MÉTODOS}

Foram avaliadas 77 ovelhas atendidas na Clínica de Bovinos, Campus Garanhuns/UFRPE, diagnosticadas com TP, no período de 2006 a 2010. Destas 51 receberam alta clínica (G1) e 26 morreram (G2). Os animais eram das raças Santa Inês, Dorper e mestiços, com idades entre um ano e meio a três anos, com peso médio de $65 \mathrm{~kg}$ e mantidos em regime de produção intensiva, recebendo diferentes tipos de concentrado em quantidade elevada. 0 escore corporal, no maior número das ovelhas, era superior a três. As ovelhas foram submetidas ao exame ultra-sonográfico para avaliação do número e viabilidade do(s) feto(s). 0 exame clínico foi realizado de acordo com Radostits et al. (20017).

Para análise das variáveis laboratoriais foram colhidas amostras de sangue por venopunção jugular em tubos siliconizados vacutainer ${ }^{\circledR}$ com fluoreto de sódio/oxalato ou sem anticoagulante para obtenção de plasma e soro, respectivamente. As amostras foram submetidas à centrifugação por um período de cinco minutos a $3.500 \mathrm{rpm}$. As alíquotas de soro e plasma foram acondicionadas em tubos tipo eppendorf e armazenadas em freezer $-80^{\circ} \mathrm{C}^{5}$ para posterior processamento laboratorial.

Foram avaliadas as atividades séricas das enzimas aspartato aminotransferase (AST), gama glutamiltransferase (GGT), fosfatase alcalina (FA) e creatina quinase (CK), bem como a concentração das proteínas totais, albumina, uréia, creatinina, colesterol, triglicerídeos e frutosamina seguindo as orientações do fabricante (Labtest Diagnóstica) ${ }^{6}$ Os ácidos graxos não esterificados (AGNE) e o $\beta$-hidroxibutirato (BHB) foram determinados de acordo com os kits comerciais (Randox Laboratories Ltd) ${ }^{7}$ e para as determin- ções hormonais de cortisol e insulina, pelo método de eletroquimioluminecência foi empregada a eletroquimioluminescência (kits comerciais Roche) ${ }^{8}$. A determinação plasmática do L-lactato (Biotécnica) ${ }^{9}$ e da glicose (Labtest Diagnóstica) ${ }^{6}$ foram realizadas de acordo com as recomendações dos respectivos fabricantes. Para a pesquisa de corpos cetônicos na urina foi empregado fitas reagentes para urinálise ${ }^{10}$ e o teste de Rothera (Dirksen 1993).

Para verificar a existência de diferenças entre as varáveis nos grupos de ovelhas que receberam alta clínica (G1) e aquelas que morreram (G2) utilizou-se análise de variância, com nível de 5\% de significância ( $\mathrm{p}<0,05 \%)$. Para aquelas não paramétricas foi empregado o teste de Wilcoxon $(\mathrm{P}<0,05 \%)$, empregando-se o programa computacional Sigma Stat (Curi 1997).

\section{RESULTADOS}

Das ovelhas diagnosticadas com TP, 51 (66,2\%) receberam alta clínica (G1) e 26 (33,8\%) morreram (G2) e destas nove morreram antes de completar a gestação. Das ovelhas diagnosticadas com TP, 51 (66,2\%) receberam alta clínica (G1) e $26(33,8 \%)$ morreram (G2) e destas nove morreram antes de completar a gestação. Foi observada gestação múltipla em $55,8 \%$ das ovelhas $(n=43)$, destas 34 prenhas de dois borregos e 9 com três. Das ovelhas estudadas, 49,3\% foram submetidas à cesariana, 40,3\% apresentaram parto eutócico e em 10,4\% foi realizou-se à manobra obstétrica. Dos 129 borregos obtidos, G1 ( $n=92)$ e G2 $(n=37)$, verificou-se um índice de sobrevivência de $68 \%$ e $54 \%$, respectivamente. Foi observada gestação múltipla em $55,8 \%$ das ovelhas $(n=$ 43), destas 34 prenhas de dois borregos e 9 com três. Das ovelhas estudadas, 49,3\% foram submetidas à cesariana, $40,3 \%$ apresentaram parto eutócico e 10,4\% submetidas à manobra obstétrica. Dos 129 borregos obtidos, G1 (n=92) e G2 (n=37), verificou-se um índice de sobrevivência de $68 \%$ e $53,8 \%$, respectivamente.

A TP provocou manifestações clínicas de intensidade diferente entre as ovelhas do G1, que receberam alta hospitalar e do G2, aquelas que morreram. Os sinais clínicos como alteração do comportamento (apatia, depressão), tremores musculares, desidratação, taquicardia, taquipnéia, inapetência a anorexia, atonia ruminal, edema nos membros posteriores e decúbito esternal foram mais acentuados nos animais que morreram. A temperatura corporal e o escore corpóreo não apresentaram diferenças entre os grupos. Sinais como amaurose, bruxismo, head pressing e olhar para estrelas foram observados em menor freqüência em ambos os grupos. As ovelhas que receberam alta hospitalar (G1) apresentaram evolução clínica de 14 dias, enquanto aque-

\footnotetext{
${ }^{5}$ Ultralow freezer NuAire Inc., 2100 Fernbrook Lane N. Plymouth, MN 55447, USA.

${ }^{6}$ Labtest Diagnóstica S.A., Av. Paulo Ferreira da Costa 600, Lagoa Santa, Minas Gerais, MG 33400-000, Brasil

${ }^{7}$ Randox Laboratories Ltd., 55 Diamond Road, Crumlin, Co. Antrim, BT29 4QY, UK.

${ }^{8}$ Elecsys Roche Diagnostics GmbH, D-68298 Mannheim, Germany.

${ }^{9}$ Biotécnica Ind. E Com. LTDA. Rua Ignácio Alvarenga 96, Vila Verônica, Varginha, MG 37026-470, Brasil.

${ }^{10}$ Multistix, Bayer S.A. Diagnóstica, Rua Domingos Jorge 1000, São Paulo, SP 04761-000, Brasil.
} 
las que morreram (G2), a evolução foi de apenas cinco dias.

Os resultados laboratoriais revelaram elevação nos valores da frutosamina, BHB, AGNE, proteína total sérica, albumina, creatinina, lactato e redução da insulina em ambos os grupos $(\mathrm{P}>0,05)$. Os valores do colesterol e dos triglicerídios mantiveram-se dentro da faixa de normalidade para a espécie, não sendo observadas alterações no G1 e no G2 $(\mathrm{P}>0,05)$. No entanto, ressalta-se maior elevação nos valores do cortisol e na concentração da uréia no G2, quando comparado ao G1 ( $\mathrm{P}<0,05)$ (Quadro 1). Quanto à glicemia, não foi observada diferença significativa entre os grupos ( $P>0,05 \%$ ) (Quadro 1), no entanto, do total de ovelhas com toxemia da prenhez, 46,8\% apresentaram hiperglicemia, $39,0 \%$ eram normoglicêmicas e apenas 14,2\% apresentavam um quadro de hipoglicemia (Quadro 2). Com relação à atividade sérica enzimática, verificou-se elevação da GGT, AST e CK que foram superiores no G2, com diferença significativa $(\mathrm{P}<0,05)$ entre os grupos na atividade da AST e

\section{Quadro 1. Valores médios, desvios padrão $(x \pm s)$ e mediana dos constituintes bioquímicos clínica e hormonais de ovelhas com toxemia da prenhez, que receberam alta clínica e as que morreram, atendidas na Clínica de Bovinos, Campus Garanhuns, UFRPE, no período de 2006 a 2010}

\begin{tabular}{lccc}
\hline \multirow{2}{*}{$\begin{array}{c}\text { Constituintes bioquímicos e } \\
\text { hormonais }\end{array}$} & \multicolumn{3}{c}{ Resolução clínica } \\
\cline { 2 - 4 } & Alta hospitalar Grupo 1 & Morte Grupo 2 & Valores de referência* $^{*}$ \\
\hline Glicose (mg/dL) & $91,77 \pm 39,38$ & $97,7 \pm 62,15$ & $50-80$ \\
Frutosamina ( $\mu$ mol/L) & $205,73 \pm 48,99$ & $209,81 \pm 52,93$ & $172 \pm 2,0$ \\
BHB (mmol/L) & $0,99 \pm 1,14$ & $0,55 \pm 0,04$ & $0-0,7$ \\
AGNE (mmol/L) & $1,02 \pm 0,67$ & $0,99 \pm 0,73$ & $<0,4$ \\
Colesterol (mg/dL) & $58,02 \pm 17,07$ & $64,3 \pm 21,86$ & $52-76$ \\
Triglicerídeos (mg/dL) & $26,04 \pm 12,77$ & $31,40 \pm 23,41$ & $9-30$ \\
L-lactato (mg/dL) & $42,7(25-75 \%)$ & $64,2(25-75 \%)$ & $9,0-12,0$ \\
PT sérica (g/dL) & $7,84 \pm 1,15$ & $7,7 \pm 1,47$ & $6,0-7,9$ \\
Albumina (g/dL) & $3,10 \pm 0,86$ & $3,00 \pm 0,71$ & $2,4-3,0$ \\
Creatinina (mg/dL) & $2,01 \pm 1,66$ & $2,7 \pm 2,71$ & $1,2-1,9$ \\
Uréia (mg/dL) & $50,62^{\mathrm{a}} \pm 34,61$ & $75,18^{\mathrm{b}} \pm 43,44$ & $17,12-42,8$ \\
AST (U/L) & $220,6^{\mathrm{a}} \pm 127$ & $306,7^{\mathrm{b}} \pm 194,2$ & $60-280$ \\
GGT (U/L) & $83,4 \pm 60,5$ & $86,3 \pm 58,2$ & $20-52$ \\
FA (U/L) & $101,7 \pm 74,7$ & $94,9 \pm 56,8$ & $68-387$ \\
CK (U/L) & $291,4^{\mathrm{a}}(25-75 \%)$ & $1069^{\mathrm{b}}(25-75 \%)$ & $8,1-12,9$ \\
Cortisol ( $\mu \mathrm{gg} / \mathrm{mL})$ & $63,8^{\mathrm{a}}(25-75 \%)$ & $135,5^{\mathrm{b}}(25-75 \%)$ & $14-22$ \\
Insulina (pmol/L) & $6,7(25-75 \%)$ & $13,0(25-75 \%)$ & $85-175$
\end{tabular}

* Fonte: Kaneko et al. (2008). Letras minúsculas diferentes nas linhas indicam diferença significativa $(\mathrm{P}<0,05)$.

Quadro 2. Valores médios e desvios padrão $(x \pm s d)$ do perfil glicêmico $(\mathrm{mg} / \mathrm{dL})$ de ovelhas com toxemia da prenhez, que receberam alta clínica e as que vieram a óbito, atendidas na Clínica de Bovinos, Campus Garanhuns, UFRPE, no período de 2006 a 2010

\begin{tabular}{ccccc}
\hline Característica & \multirow{2}{*}{$\begin{array}{c}\text { Glicose } \\
(\mathrm{mg} / \mathrm{dL})\end{array}$} & \begin{tabular}{c} 
Número de animais \\
\cline { 3 - 5 }
\end{tabular} & $(\%)$ & \multicolumn{2}{c}{ Número de casos $(\%)$} \\
\hline Hiperglicêmica & $130,57 \pm 33,6$ & $36(46,8 \%)$ & $22(43,1 \%)$ & $14(53,8 \%)$ \\
Normoglicêmica & $69,82 \pm 13,8$ & $30(39,0 \%)$ & $22(43,1 \%)$ & $8(30,8 \%)$ \\
Hipoglicêmica & $36,42 \pm 8,1$ & $11(14,2 \%)$ & $7(13,7 \%)$ & $4(15,4 \%)$
\end{tabular}

da CK. Os valores da FA se mantiveram situados na faixa de normalidade para a espécie (Quadro 1).

Apesar de não ter ocorrido diferença entre os grupos $(\mathrm{P}>0,05)$, todas as ovelhas $(100 \%)$ apresentaram cetonúria e valores de mediana do $\mathrm{pH}$ urinário de 6,0.

\section{DISCUSSÃO}

Os achados clínicos encontrados nas ovelhas com toxemia da prenhez foram relatados por outros autores como frequentes na evolução da doença e ratificados como indicadores de prognóstico ruim, quando apresentados de forma mais intensa, fato este constatado naquelas ovelhas que morreram. Os sinais nervosos relatados foram também descritos nos casos naturais da doença (Bruere \& West
1993, Rook 2000, Radostits et al. 2007, Campos et al. 2010). Nas ovelhas acometidas por TP os valores encontrados para glicose apresentando três variações, , contradiz alguns relatos sobre o comportamento desta variável na patogenia da doença, em que a hipoglicemia é a anormalidade inicialmente mais detectada (Kranfield 1972, Wastney et al. 1983, Scott et al. 1995, Andrews 1997, Barakat et al. 2007). Entretanto, em alguns casos naturais de TP relatados, a hipoglicemia parece ser consequência da hipercetonemia e da inapetência, antes de ser considerada a causa dessas mudanças (Andrews et al. 1996, Henze et al. 1998). 0 estado de hiperglicemia, constatado como achado mais frequente, pode ser explicado pela condição de estresse das ovelhas, constatado pelos 
elevados índices de cortisol encontrados, que resultam numa gliconeogênese, e que se tornam mais acentuados quando ocorre a morte dos fetos, como ocorrido nas ovelhas em ambos os grupos (Ford et al. 1990). Outro fator, que ainda não está bem definido, que pode ser considerado por contribuir com este resultado, seria os valores baixos verificados para insulina e elevados de AGNE, esta condição tem sido postulada como resultado da criação de um ambiente no qual se suporta a minima utilização de glicose pelos tecidos periféricos e seu máximo uso pelo útero grávido, ou seja, a sensibilidade dos tecidos periféricos para insulina está reduzida e a mobilização de tecido adiposo para produzir AGNE como fonte alternativa de energia para a ovelha está elevada, esta alteração pode reforçar a hipótese de que ocorra uma insuficiência na regulação hormonal do metabolismo de lipídeos e da glicoestase como causa da TP, durante a sua evolução nas ovelhas (Lomax et al. 1979, Pethick et al. 1983, Sigurdsson 1991, Peterson et al. 1993).

0 valor elevado da frutosamina pode ser justificado como consequência do quadro de hiperglicemia observado em $46,9 \%$ dos animais e aos valores da albumina que encontravam-se dentro da faixa de normalidade para a espécie em ambos os grupos. Este resultado vai de encontro ao relatado por Cantley et al. (1991) que encontraram um menor valor para esta variável, em ovelhas com TP, e que estava associada ao quadro de hipoglicemia e aos valores normais para albumina. Esta contradição nos achados do trabalho pode ser explicada pelo fato de ser a frutosamina uma quetoamina estável, que é formada quando a glicose reage não enzimaticamente com grupos aminas das proteínas, principalmente a albumina, e sua concentração no plasma ou sérica é controlada pelo balanço entre a síntese e eliminação destes compostos protéicos e com a glicose. Todavia, se a concentração da proteína está dentro da normalidade, os índices de frutosamina estão relacionados aos níveis de glicose plasmática que se modificaram a 3 e 4 semanas. Deste modo, os níveis de frutosamina aumentam numa prolongada hiperglicemia, condição esta que provavelmente tenha ocorrido com as ovelhas acometidas neste trabalho, ou prolongada hiperproteinemia, mas podem reduzir numa condição inversa (Bernstein 1987, Jensen et al. 1992, Kaneko et al. 2008).

Os índices elevados para o BHB foram observados em outros relatos, porém com diferenças quanto aos valores descritos (Ford et al. 1990, Cantley et al. 1991, Jeffrey \& Higgins 1992, Scott et al. 1995, Henze et al. 1998). Os resultados obtidos são justificados por uma deficiência na produção e uso da glicose, que cria um sinal lipolítico, e a partir dos tecidos adiposos aumenta a liberação de ácidos graxos não esterificados (AGNE), e esta elevação no sangue, estimula o mecanismo de oxidação pelo fígado à produção de corpos cetônicos (Schlumbohm \& Harmeyer 2004, Kaneko et al. 2008). 0 aumento sanguíneo da concentração BHB (hipercetonemia) está relacionado com a gravidade da doença, como verificado nas ovelhas acometidas. Como regra para o BHB, alguns autores consideram que em rebanhos quando os níveis excedem $0,7 \mathrm{mmol} / \mathrm{L}$, o potencial para o surgimento dos casos clínicos de toxemia da prenhez eleva-se (Andrews 1997, Morghaddam \& Hassanpour, 2008).

As concentrações elevadas para o AGNE retratam a condição clínica do transtorno metabólico, e são explicados pela lipólise ocorrida, indicando com isso existir uma mobilização de gordura para atender uma maior demanda de energia por parte das ovelhas e dos fetos. Fato como este foi relatado em trabalhos sobre a ocorrência natural de TP em ovelhas e cabras, em que demonstraram a elevação nos valores deste componente, que variaram entre 0,29 e 1,91mmol/L. (Sigurdsson 1991, Sargison et al. 1994, Van Sauan 2000, Barakat et al. 2007). A justificativa para a elevação do AGNE está relacionada ao balanço energético negativo na dieta das ovelhas durante o período do periparto, em resposta a esta condição há um aumento na liberação deste componente na circulação a partir do tecido adiposo, mediada pela ação de lípase, onde é transportado ao fígado e sofre um processo de oxidação formando corpos cetônicos (Jakson \& Winkler 1969, Sargison et al. 1994, Kaneko et al. 2008). Condição esta que provavelmente tenha ocorrido nas ovelhas com a doença neste estudo.

Segundo Regnault et al. (2004), há outros aspectos a considerar com relação ao aumento da concentração dos AGNE, na condição de cronicidade em ovelhas acometidas com TP, e a regulação na produção de insulina. Em primeiro lugar, seria que eles serviriam como uma fonte alternativa de combustível para o metabolismo materno. Em segundo lugar, eles agiriam no sentido de promover o desenvolvimento de um estado de resistência à insulina, o qual é auxiliado pela supressão da resposta da glicose estimulando a liberação de insulina. Esta ação ainda não está bem esclarecida na gestação, mas poderia ser o resultado de interações entre hormônios produzidos durante este período e pelo pâncreas materno. Em função do aumento da resistência à insulina nos tecidos periféricos materno e uma redução na produção de insulina, a glicose é "poupada" e com isso torna-se mais disponível o seu uso para atender a demanda fetal.

Apesar dos valores obtidos para o colesterol encontrarem-se dentro do limite inferior da normalidade para a espécie ovina, há uma tendência em ocorrer uma redução na concentração desta variável nos animais acometidos (Kaneko et al. 2008). Esta alteração é sugestiva de que a habilidade do fígado de secretar este composto no sangue como lipoproteína (VLDL) está comprometida, induzindo desta maneira o acúmulo de gordura hepática. Esta modificação metabólica associada aos valores elevados do AGNE e a alta ocorrência das ovelhas apresentando escore corporal elevado, acima de três, contribui para o desencadeamento da enfermidade (Van Saun 2000).

Com relação a concentração para triglicerídeos, que se manteve dentro dos valores de referência para espécie (Kaneko et al. 2008), estes achados se assemelham ao relatado por Van Saun (2000), que não encontrou também alterações nos índices deste componente em ovelhas com toxemia da prenhez. Entretanto, diferenças foram relatadas por Barakat et al. (2007) em cabras com cetose, que relataram valores baixos de triglicerídeos e fosfolipídios, e 
concluíram que são resultados da redução do apetite nos animais com hipercetonemia.

Com relação à elevação da proteína total sérica, os achados se comparam ao encontrado em outros trabalhos, que justificam esta alteração em função dos diferentes graus de desidratação encontrados nos animais acometidos, condição esta observada nas ovelhas com TP (Cantley et al 1991, Andrews et al. 1996, Van Saun 2000, Smith \& Sherman 2009). Os achados diferem dos relatados por Yarin \& Ceftci (2009) em ovelhas acometidas com a doença, em que reduções nos seus valores foram encontradas e concluíram esta modificação pelo comprometimento da função hepática, em função da redução da síntese da albumina.

Nos resultados encontrados para albumina, em ambos os grupos (G1 e G2), constataram-se que se assemelham aos relatados por de Cantley et al. (1991) e Van Saun (2000), em ovelhas diagnosticadas co TP, em que não houve alteração em relação aos índices de normalidade para a espécie. Segundo Andrews et al. (1996), alterações nos índices da albumina no sangue estão relacionadas a problemas crônicos ou mudanças agudas na hidratação do animal, e por ter uma meia vida longa, os seus níveis sanguíneos em ovelhas com toxemia da prenhez, apresentando evolução aguda, não diferem das ovelhas sadias no mesmo estágio da gestação.

As alterações nos índices da creatinina e uréia caracterizando um quadro de azotemia foram relatadas, em cabras e ovelhas com TP em diferentes intensidades, por Wastney et al. (1983), Andrews et al. (1996), Sargison et al. (1994), Van Saun (2000), Barakat et al. (2007) e Yarin \& Ciftci (2009), que relataram a má função renal e o catabolismo protéico como causa da elevação nos valores destes indicadores da função renal. Esta alteração pode ser explicada por observações feitas por Ferris et al. (1969) e Marteniuk \& Herdt (1988), que encontraram infiltração excessiva de gordura no epitélio tubular acarretando modificações estruturais glomerulares, provocando uma degeneração dos rins em ovelhas com a doença, e que podem prejudicar a função renal. Teores elevados de creatinina e de uréia são indicativos de um quadro de insuficiência renal, que pode ser severo no estágio terminal e está associado com o prognóstico reservado, como foi observado no grupo das ovelhas que morreram.

Os índices encontrados para o L-lactato mostraram um quadro de lacticidemia expressiva, compatível com um quadro de acidose metabólica, observada em animais acometidos seriamente com este distúrbio (Reid 1968, Barakat et al. 2007). Diferente do observado por Ferris et al. (1969), que não encontraram elevações do L-lactato sanguíneo e nem um quadro de acidose metabólica expressiva em ovelhas acometidas com a doença. A condição, verificada nas ovelhas com TP no trabalho, é justificada pela cetonemia, que surge como conseqüência ao processo de oxidação exacerbada dos AGNE, que gera a produção excessiva de corpos cetônicos (acetoacetato, acetona e BHB), e como estes são ânions com características ácidas, elevam o "anion Gap" e reduzem a concentração de $\mathrm{HCO}-, \mathrm{CL}, \mathrm{Na}+\mathrm{e}$ $\mathrm{K}+$, com isso a acidose metabólica ocorre. Associado a este transtorno, a desidratação que foi também observada nos animais, desencadeia o processo glicolítico (glicose anae- róbica) produzindo lactato a partir da glicose, contribuindo para o quadro da lacticidemia (Naylor et al. 1984, Kaneko et al. 2008).

Os valores encontrados para o cortisol sérico, e as diferenças existentes entre os grupos caracterizam o estado de estresse em que se encontravam as ovelhas numa condição clínica de intensidade variada, verificada entre os animais analisados, com maior gravidade nas ovelhas que morreram. Tal condição também foi relatada, por alguns autores, em cabras e ovelhas com TP, que justificaram este aumento como decorrente da maior produção deste hormônio pela glândula adrenal, em resposta ao severo estresse observado na doença e/ou pela habilidade prejudicada do fígado gordo em metabolizá-lo e excretá-lo (Lindner 1959, Ford 1990, Sigurdsson 1991, Henze et al. 1994, Henze et al. 1998, Hefnawy et al. 2010). Um dos principais efeitos dos glicocorticóides é promover o estoque de glicogênio hepático, que é atribuído a intensificação da gliconeogêneses, da hiperglicemia e o decréscimo na glicogenolises (Radostits et al. 2007, Kaneko et al. 2008).

Os resultados obtidos para insulina são ratificados com as informações encontradas por alguns autores que verificaram em ovelhas com TP um quadro de hipoinsulinemia, tendo como causa provável a interferência de fatores hormonais (lactogênicos e esteróides) e metabólitos como o AGNE, influenciando sobre a fisiologia do pâncreas, suprimindo a resposta da insulina maternal durante a enfermidade (Brockman 1979, Sigurdsson 1991, Henze et al. 1994, Henze et al. 1998, Bergman 2000, Rook 2000, Regnault et al. 2004). Fato este bem caracterizado neste trabalho pelos índices elevados de cortisol, AGNE, BHB e a hiperglicemia. As ações compartilhadas destes componentes (hormonais e metabólicos) não estão ainda bem definidas na doença, mas poderão influenciar na intensidade da cetôgenese e na desordem da glicoestases. Entretanto os achados do trabalho, destoam do encontrado por Hefnawy et al. (2010), em cabras com toxemia da prenhez induzida experimentalmente, nas quais encontraram uma elevação nos índices de insulina e justificaram como um mecanismo compensatório para suprimir a cetogênese. É bem conhecida a ação da insulina suprimindo a cetogênese, regulando a utilização de corpos cetônicos pelos tecidos da ovelha.

Quanto à cetonúria, este fato também foi relatado por Silva et al. (2008) e Campos et al. (2010), que verificaram a presença de corpos cetônicos na urina de ovelhas com a doença. A presença destes compostos na urina é condizente com as afirmativas de Lynch \& Jackson (1983) e Wastney et al. (1983), quando relataram que este é um dos achados mais consistentes na toxemia da prenhez em ovinos, enfatizando que a concentração de ß-hidroxibutirato (BHB) em ovelhas gestantes normais apresenta valores abaixo de $0,5 \mathrm{mmol} / \mathrm{L}$, enquanto que a cetonúria é evidente somente quando a concentração plasmática de BHB alcança valores acima de $0,7 \mathrm{mmol} / \mathrm{L}$. Entretanto, Leng (1966) com o intuito de obter observações adicionais sobre o metabolismo dos corpos cetônicos na ovelha gestante toxêmica, relatou que pouca ou nenhuma acetona foi excretada na respiração e na urina. Tal diferença é provável que esteja relacionada à magnitude da manifestação clínica da enfermidade. 
0 quadro de acidúria, encontrado na maioria dos animais acometidos, é relatado por Ortolani (1985), como um achado frequente, podendo chegar a valores próximos a cinco.

Considerações, sobre as alterações de parâmetros bioquímicos e hormonais encontrados neste estudo, poderão ser feitas a respeito na dinâmica da fisiopatologia da toxemia da prenhez nas ovelhas, em casos naturais, que ainda é pouco esclarecida. Seria importante enfatizar, que enquanto os desequilíbrios metabólicos e hormonais podem ser considerados a peça central para o surgimento da cetose, são apenas secundários a inabilidade da dieta ofertar suficiente substrato para atender a demanda energética durante a gestação e lactação. Estas alterações representam apenas ajustes feitos pelas ovelhas para mobilizar estoques de energia e mobilizar glicose para ser usada pelo conteúdo uterino e/ou glândula mamária. $\mathrm{Na}$ ovelha, com o surgimento da doença, a condição clínica é complexa, ela não tem como parar a demanda do feto e sem a remoção pelo parto ou cirúrgica dos cordeiros, em algumas situações de forma prematura, o prognóstico é grave.

\section{CONCLUSÃO}

Diante dos achados obtidos neste trabalho com relação às ovelhas acometidas com TP em condições naturais, foi constatado que o fenômeno provoca transtornos no perfil metabólico (energético e protéico) e hormonal, com sua expressão maior nos aspectos clínicos observados e nas perdas ocorridas pelas mortes dos fetos e ovelhas.

Agradecimentos.- Ao Conselho Nacional de Desenvolvimento Científico Tecnológico (MCT/CNPq, Edital Universal 14/2009, Proc.480949/20093) e à Fundação de Amparo à Pesquisa do Estado de Pernambuco (FACEPE) pela concessão da Bolsa de Mestrado (Edital PBPG13/2008 - IBPG 1341-5.05-08).

\section{REFERÊNCIAS}

Andrews A. 1997. Pregnancy toxaemia in the ewe. In Practice 19:306-312.

Andrews A.H., Holland-Howes V.E. \& Wilkinson J.I.D. 1996. Naturally occurring pregnancy toxaemia in the ewe and treatment with recombinant bovine somatotropin. Small Rum. Res. 23:191-197.

Barakat S.E.M., AL-Bhanasawi N.M., Elazhari G.E. \& Bakhict A.O. 2007. Clinical and serobiochemical studies on naturally occurring pregnancy toxaemia in Shama goats. J. Anim. Vet. Adv. 6(6):768-772.

Bernstein R.E. 1987. Nonenzymatically glycation of proteins. Adv. Clin. Chem. 26:1-78.

Betgman R.N. 2000. Non-esterified fatty acids and the liver: Why is insulin secreted into the portal vein? Diabet. 43:946-952.

Brockman R.P. 1979. Roles for insulin and glucagon in the development of ruminant ketosis: A review. Can. Vet. J. 20(5):121-126.

Bruére A.N. \& West D.M. 1993. The Sheep: Health, disease and production. Massey University, Palmerston North, New Zealand. 397p.

Campos A.G.S., Afonso J.A.B., Dantas A.C., Santos R.A. Guimarães J.A. \& Mendonça C.L. 2010. Estudo clínico da toxemia da prenhez em ovelhas: análise de 33 casos. Ciênc. Anim. Bras. 11(3):623-628.

Cantley C.E.L., Ford C.M. \& Heath M.F. 1991. Serum fructosamine in ovine pregnancy toxaemia: A possible prognostic index. Vet. Rec. 128(6):525526.

Curi P.R. 1997. Metodologia e Análise da Pesquisa em Ciências Biológicas. Tipomic, Botucatu. 263p.
Dirksen G., Grunder H.D., Stober M. 1993. Rosenberger: Exame clinico dos bovinos. 3르 ed Guanabara Koogan, Rio de Janeiro, 419p.

Ferris T.F., Herdson P.B., Dunnill M.S. \& Lee M.R. 1969. Toxemia of pregnancy in sheep: A clinical, physiological, and pathological study. J. Clin. Invest. 48:1643-1655.

Ford E.J., Evans J. \& Robinson I. 1990. Cortisol in pregnancy toxemia of sheep. Brit. Vet. J. 146(6):539-542.

Hefnawy A.B., Youssef S. \& Shousha S. 2010. Some immunohormonal changes in experimentally pregnant toxemic goats. Vet. Med. Int. 4:1-5.

Herdt T.H. 1988. Fuel homeostasis in ruminants. Vet. Clin. North Am., Food Anim. Pract. 2:213-231.

Henze P., Biickhardt K. \& Fuhrmann H. 1994. The influences of insulin, cortisol, growth hormone and total oestrogen on the pathogenesis of ketosis in sheep. Dtsch. Tierärztl. Wochenschr. 101:61-65.

Henze P., Biickhardt K., Fuhrmann H. \& Sallman H.P. 1998. Spontaneous pregnancy toxaemia (ketosis) in sheep and the role of insulin. J. Am. Vet. Med. Assoc. 45:225-226.

Jackson F.D. \& Winkler V.W. 1969. Effects of starvation on the fatty acid composition of adipose tissue and plasma lipids of sheep. J. Nutr. 100: 201-207.

Jeffrey M. \& Higgins R.S. 1992. Brain lesions of naturally occurring pregnancy toxemia of sheep. Vet. Pathol. 29(4):301-307.

Jensen A.L. 1992. Serun fructosamine in canine diabetes mellitus: An initial study. Vet. Res. Commun. 16: 1-9.

Kaneko J.J., Harvey J.W. \& Bruss M.L. 2008. Clinical Biochemistry of Domestic Animals. $6^{\text {th }}$ ed. Academic Press, San Diego. 916p.

Kronfeld D.S. 1972. Ketosis in pregnancy sheep and lactating in ewes: A review. Aust. Vet. J. 48:301-307.

Kimberling C.V. 1988. Jensen and Swift's diseases of sheep. $3^{\text {rd }}$ ed. Lea and Febiger, Philadelphia. 394p.

Lindner H.R. 1959. Blood cortisol in sheep: Normal concentration and changes in ketosis of pregnancy. Nature 184:1645-1646.

Lomax M.A., Baird G.D., Mallinson C.B. \& Symonds H.W. 1979. Differences between lactating and non-lactating dairy cows in concentration and secretion rate of insulin. Biochem. J. 180:281-289.

Marteniuk J.V. \& Herdt T.H. 1988. Pregnancy toxemia and ketosis of ewes and does. Vet. Clin. North Am., Food Anim. Pract. 4(2):307-315.

Moghaddam G. \& Hassanpour A. 2008. Comparison of blood serum glucose, beta htdroxybutyric acid, blood urea nitrogen and calcium concentrations in pregnant and lambed ewes. J. Am. Vet. Adv. 7(3):308311.

Naylor J.M., Kronfeild D.S. \& Freeman D.E. 1984. Hepatic and extrahepatic lactate metabolism in sheep: Effects of lactate loading on $\mathrm{pH}$. Anim. J. Phys. 8:E747-E755.

Ortolani E.L. 1985. Toxemia da prenhez, p.201-210. In: Ibid. (Ed.), Manejo, Patologia e Clínica de Caprinos. Sociedade Paulista de Medicina Veterinária - Unesp, São Paulo. (Apostila)

Ortolani E.L. \& Benesi F.J. 1989. Ocorrência de toxemia da prenhez em cabras (Capra hircus L.) e ovelhas (Ovis aries L.) criadas no estado de São Paulo, Brasil. Revta Fac. Med. Vet. Zootec. USP 26(2):229-234.

Petterson J.A., Dunshea F.R., Ehrhardt R.A. \& Bell A.W. 1993. Pregnancy and undernutrition alter glucose metabolic responses to insulin in sheep. .J Nutr. 123:1286-1295.

Pethick D.W., Lindsay D.B., Barker P. J. \& Northrop A. J. 1983. The metabolism of circulating non-esterified fatty acids by the whole animal, hind-limb muscle and uterus of pregnant ewes. Br. J . Nutr. 49:129143.

Radostits O.M., Gay C.C., Hinchcliff K.W. \& Constable P.D. 2007. Veterinary Medicine: A textbook of the diseases of cattle, horses, sheep, pigs and goats. $10^{\text {th }}$ ed. W.B. Saunders, Edinburgh. 2156p.

Regnault T.R.H., Oddy H.V., Nancarrow C., Sriskandarajad N. \& Scaramuzzi R.J. 2004. Glucose-stimulated insulin response in pregnant sheep following acute suppression of plasma non-esterified fatty acid concentrations. Rep. Biol. Endocrinol. 2(64):1-10. 
Reid R.L. 1968 The physiopathology of undernourishment in pregnant sheep, with particular reference to pregnancy toxaemia. Adv. Vet. Sci. 12:163-238.

Rook J.S. 2000. Pregnancy toxemia of ewes, does and beef cows. Vet. Clin. North Am.. Food Anim. Pract. 16(2):293-317.

Sargison N.D., Scott P.R., Penny C.D., Pirie R.S. \& Kelly J.M. 1994. Plasma enzymes and metabolites as potential prognostic indices of ovine pregnancy toxaemia: A preliminary study. Brit. Vet. J. 150(3):271-277.

Scott P.R., Sargisson N.D., Penny C.D., Pirie R.S. \& Kelly J.M. 1995. Cerebrospinal fluid and plasma glucose concentrations of ovine pregnancy toxaemia cases, inappetant ewes and normal ewes during late gestation. Brit. Vet. J. 151:39-44.

Schlumbohm C. \& Harmeyer J. 2004. Hyperketonemia impairs glucose metabolism in pregnant and nonpregnant ewes. J. Dairy Sci. 87:350358
Sigurdsson H. 1991. Metabolic disorders in ewes during late pregnancy. Iceland Agric. Sci. 5:25-31.

Silva T.V., Sandrini C.N.M., Corrêa F.A.F. \& Prado R.S. 2008. Alterações clínicas, laboratoriais e tratamento da toxemia da prenhez em pequenos ruminantes. Disponível em <www.sovergs.com.br/conbravet2008/anais/ cd/resumos/R0659-1.pdf> Acesso em 6 dez. 2008.

Smith M.C. \& Sherman D. 2009. Goat Medicine. $2^{\text {nd }}$ ed. Lea and Febiger, Philadelphia. 871p.

Van Saun R.J. 2000. Pregnancy toxemia in a flock of sheep. J. Am. Vet. Med. Assoc. 21(10):1536-1539.

Wastney M.E., Wolff J.E. \& Bickerstaffe R. 1983. Glucose turnover and hepatocyte glucose production of starved and toxaemic pregnant sheep. Aust. J. Biol. Sci. 36:271-284.

Yarin G.F. \& Ciftci G. 2009. Serum pattern in ewe with pregnancy toxemia. Vet. Res. Commun. 33:431-438. 